\title{
Kajian Teknologi dan Mekanisme Stabilisasi/Solidifikasi untuk Pengolahan Limbah B3
}

\author{
Royyan Anrozi dan Yulinah Trihadiningrum \\ (ITS) \\ Jl. Arief Rahman Hakim, Surabaya 60111 Indonesia \\ e-mail: yulinah_t@enviro.its.ac.id
}

Departemen Teknik Lingkungan, Fakultas Teknik Sipil dan Perencanaan, Institut Teknologi Sepuluh Nopember

\begin{abstract}
Abstrak-Pencemaran tanah oleh limbah bahan berbahaya dan beracun (B3) sering terjadi akibat aktivitas manusia. Salah satu teknologi untuk pengolahan limbah B3 adalah stabilisasi/solidifikasi (S/S). Tujuan dari penulisan artikel ini adalah mengidentifikasi teknologi dan mekanisme aplikasi proses S/S dalam pengolahan limbah B3. Artikel ini disusun dengan mengumpulkan data terkait stabilisasi/solidifikasi dari berbagai sumber pustaka. Sumber pustaka yang digunakan berupa text book, jurnal ilmiah nasional dan internasional. Teknologi S/S terbagi menjadi tiga bagian yaitu $S / S$ secara fisik, kimia, dan termal. S/S secara fisik tidak melibatkan reaksi kimia. S/S secara kimia memerlukan reaksi kimia untuk memungkinkan proses S/S berlangsung. S/S secara termal (vitrifikasi) menggunakan panas untuk melelehkan dan mensolidifikasi senyawa berbahaya pada massa yang solid seperti bahan-bahan yang mempunyai sifat seperti gelas. Teknologi stabilisasi/solidifikasi yang dapat diterapkan untuk pengolahan limbah B3 adalah kapsulasi mikro, vitrifikasi, dan stabilisasi/solidifikasi secara kimia. Kapsulasi mikro efektif untuk meremediasi tanah berpasir yang terkontaminasi kontaminan hidrokarbon. Vitrifikasi secara termal mampu digunakan untuk meremediasi tanah tercemar limbah B3 baik organik maupun anorganik. Imobilisasi kontaminan dilakukan dengan cara mengubah limbah menjadi gelas atau bahan kristalin. S/S berbasis semen portland dan pozzolan baik diterapkan untuk remediasi tanah tercemar limbah $\mathrm{B3}$ dengan $\mathrm{pH}$ rendah dan mengandung senyawa halida. $\mathrm{S} / \mathrm{S}$ berbasis pozzolan juga mampu mengatasi kontaminan mengandung senyawa sulfat. Mekanisme S/S adalah mengurangi sifat berbahaya kontaminan dengan cara mengurangi laju migrasi dan toksisitasnya.
\end{abstract}

Kata Kunci-limbah B3, mekanisme S/S, stabilisasi/solidifikasi, tanah tercemar, teknologi $\mathrm{S} / \mathrm{S}$

\section{PENDAHULUAN}

$\mathrm{T}$ ANAH merupakan lingkungan yang penting dimana batuan, udara, dan air saling berinteraksi. Oleh karena itu tanah menjadi subjek berbagai macam polusi yang disebabkan oleh berbagai aktifitas manusia termasuk industri [1]. Pencemaran adalah suatu kondisi yang telah berubah dari kondisi asal ke kondisi yang lebih buruk sebagai akibat masukan dari bahan-bahan pencemar atau polutan [2]. Tanah yang tercemar dapat menjadi penyebab timbulnya penyakit baik penyakit menular maupun tidak menular [3]. Dalam berbagai kasus, pencemaran tanah juga disebabkan oleh limbah bahan berbahaya dan beracun (B3).

Solusi baru dan inovatif untuk menghilangkan kontaminan B3 dari tanah dari limbah secara efisien telah diselidiki selama beberapa tahun terakhir [4]. Salah satu solusi untuk mengatasinya adalah stabilisasi/solidifikasi (S/S) dari limbah padat dengan cara menambahkan pengikat semen, seperti kapur dan semen. Selama aplikasi S/S, senyawa beracun yang ada pada limbah akan stabil secara fisik dan kimia. Artinya mobilitas senyawa beracun secara signifikan berkurang hingga meminimalkan ancaman terhadap lingkungan [5].

\section{METODE STUDI}

Artikel ini disusun dengan mengumpulkan data dari berbagai sumber pustaka. Sumber pustaka yang digunakan berasal dari text book, jurnal ilmiah nasional dan internasional yang berkaitan dengan topik stabilisasi/solidifikasi.

\section{STABILISASI/SOLIDIFIKASI}

Stabilisasi/solidifikasi (S/S) merupakan proses yang melibatkan pencampuran limbah dengan zat pengikat untuk mereduksi pelindian kontaminan baik secara fisik dan kimia. Proses S/S mengkonversi limbah (B3) menjadi bentuk limbah yang dapat diterima oleh lingkungan untuk dibuang ke lahan pembuangan atau digunakan untuk keperluan konstruksi. S/S telah banyak digunakan untuk menangani limbah radioaktif tingkat rendah, berbahaya, dan limbah campuran [6].

\section{A. Definisi Stabilisasi/Solidifikasi}

"Stabilisasi" adalah proses penambahan bahan aditif atau reagensia yang bertujuan untuk mengurangi sifat beracun limbah, dengan cara mengubah limbah dan komponen berbahayanya ke bentuk yang dapat mengurangi laju migrasi kontaminan ke lingkungan, atau mengurangi sifat beracun limbah tersebut. Sedangkan "solidifikasi" adalah proses ditambahkannya bahan yang dapat memadatkan limbah agar terbentuk massa limbah yang padat [7].

Solidifikasi dan stabilisasi dapat dicapai dengan reaksi kimia antara limbah dan reagen pemadat atau dengan proses mekanis. Migrasi kontaminan biasanya dibatasi dengan mengurangi luas permukaan yang terkena pelindian atau dengan melapisi limbah dengan material yang memiliki permeabilitas rendah [6].

Bahan pengikat kontaminan dalam limbah yang sering digunakan adalah pozzolan. Pozzolan adalah bahan alam atau buatan yang sebagian besar kandungannya terdiri atas unsurunsur silika dan alumina atau keduanya [8].

\section{B. Tujuan Stabilisasi/Solidifikasi}

Tujuan dari proses stabilisasi/solidifikasi adalah mengkonversi limbah beracun menjadi massa yang secara fisik inert, memiliki daya leaching rendah, serta kekuatan 
mekanik yang cukup agar aman untuk dibuang ke landfill limbah B3 [7]. Leaching atau pelindian adalah proses dimana kontaminan ditransfer dari matriks yang stabil menjadi sebuah zat cair seperti air [9].

Karakteristik yang diharapkan dimiliki oleh produk stabilisasi diantaranya [7]:

1) Stabil.

2) Mampu menahan beban.

3) Toleran terhadap kondisi basah dan kering yang silih berganti.

4) Permeabilitas rendah.

5) Tidak menghasilkan lindi yang berkualitas buruk.

Teknik remediasi menggunakan proses $\mathrm{S} / \mathrm{S}$ memiliki beberapa keuntungan antara lain [10]:

1) Kemudahan dalam penerapan dan pengolahannya.

2) Mempunyai stabilitas fisik dan kimia jangka panjang yang baik.

3) Mempunyai kekuatan kompresi yang baik.

4) Resisten terhadap biodegradasi.

5) Memiliki permeabilitas air yang rendah.

Proses stabilisasi biasa digunakan untuk:

1) Stabilisasi limbah cair $B 3$ sebelum dibuang ke landfill.

2) Remediasi lahan-lahan yang terkontaminasi limbah B3.

Prosedur stabilisasi/solidifikasi adalah sebagai berikut:

1) Sebelum dilakukan stabilisasi/solidifikasi, limbah B3 harus ditentukan karakteristiknya terlebih dahulu guna menentukan komposisi bahan-bahan yang perlu ditambahkan.

2) Setelah dilakukan stabilisasi/solidifikasi, selanjutnya dilakukan uji Toxicity Characteristic Leaching Procedure (TCLP) terhadap hasil olahan tersebut untuk mengukur konsentrasi parameter dalam lindi (extract/eluate); hasil uji TCLP sebagaimana dimaksud, kadarnya tidak boleh melewati nilai baku mutu.

3) Hasil stabilisasi selanjutnya diuji kuat tekan (compressive strength); nilai tekanan minimum sebesar $10 \mathrm{ton} / \mathrm{m}^{2}$, dan lolos uji paint filter test.

4) Hasil stabilisasi yang memenuhi persyaratan baku mutu TCLP, nilai uji kuat tekan dan paint filter test harus ditimbun di tempat penimbunan (landfill) B3.

\section{TEKNOLOGI STABILISASI/SOLIDIFIKASI}

Menurut Spence dan Shi [6] teknologi S/S terbagi atas S/S secara fisik, kimia, dan termal. S/S secara fisik adalah proses S/S yang tidak melibatkan reaksi kimia. Proses dapat berlangsung dengan adsorpsi atau absorpsi suatu zat pada permukaan atau pori-pori, atau mengkapsulasi limbah pada matriks pembungkus. Teknologi ini memisahkan zat berbahaya dari lingkungan secara fisik. Contoh S/S secara fisik adalah kapsulasi makro, kapsulasi mikro, dan kapsulasi termoplastik.

S/S secara kimia adalah proses S/S yang memerlukan reaksi kimia untuk memungkinkan proses $\mathrm{S} / \mathrm{S}$ berlangsung. Sebagian besar proses S/S secara kimia melibatkan reaksi bahan semen atau pozzolan yang sangat kompleks.

S/S secara termal adalah proses $\mathrm{S} / \mathrm{S}$ yang menggunakan panas untuk melelehkan dan mensolidifikasi senyawa berbahaya pada pada massa yang solid seperti bahan-bahan yang mempunyai sifat menyerupai gelas. S/S secara termal juga disebut vitrifikasi.

\section{A. Kapsulasi Makro}

Kapsulasi makro didefinisikan dengan pembungkusan limbah B3 dalam kapsul pembungkus yang inert \& kedap air. Bahan pembungkus dapat berupa campuran fiberglass, resin epoksida, dan resin polyurethane [7]. Limbah B3 tertahan dalam matriks yang terbentuk dari material stabilisasi [9]. Umumnya jenis limbah yang diolah dengan teknologi ini adalah limbah berbahaya berbentuk potongan-potongan. Teknologi ini termasuk dalam teknologi S/S secara fisik.

Gambar 1adalah contoh dari potongan-potongan limbah yang terstabilisasi sebagai hasil dari kapsulasi makro. Limbahlimbah tersebut mengandung logam, kayu, balok, bebatuan, dan plastik dengan berbagai bentuk dan ukuran. Beberapa limbah sudah dipotong dalam bentuk yang lebih kecil sehingga dapat dengan mudah dimasukkan ke drum berukuran 2 gal (7,57 Liter). Potongan-potongan limbah tersebut diikat dengan mencampurkan limbah dengan bubur keramik fosfat yang sudah disiapkan. Bubur keramik fosfat disiapkan dengan cara mengaduk bubuk magnesium oksida terkalsinasi dan debu terbang (fly ash) dengan larutan asam fosfat (potassium fosfat) pada pengaduk berkapasitas 5 gal (18,93 Liter). Perbandingan dari campuran bubur keramik adalah $40 \%$ debu, $40 \%$ binder $\left(\mathrm{MgO}\right.$ dan bubuk $\mathrm{KH}_{2} \mathrm{PO}_{4}$ yang dicampur dengan perbandingan molar 1:1) dan 20\% air. Setelah diaduk dengan kecepatan rendah (30-40 rpm) selama 30 menit, bubur keramik fosfat dituang ke drum berisi limbah sambil diaduk terus-menerus agar campuran homogen [11].

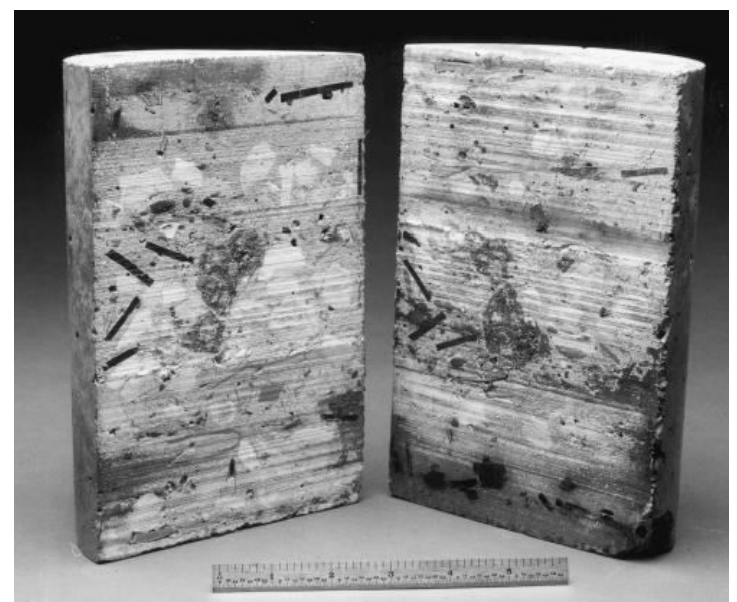

Gambar 1. Kapsulasi Makro Potongan-Potongan Limbah Heterogen dengan Keramik Fosfat [11]

\section{B. Kapsulasi Mikro}

Kapsulasi mikro melibatkan pengadukan antara limbah dan bahan pembungkus sebelum pemadatan terjadi [12]. Limbah B3 terbungkus dalam struktur kristalin dari matriks tersolidifikasi pada level mikroskopis. Sebagian besar limbah B3 yang terstabilisasi tetap terperangkap meskipun bahan yang terstabilisasi terdegradasi menjadi partikel berukuran kecil [9]. Kapsulasi mikro efektif digunakan untuk tanah tercemar senyawa hidrokarbon $[9,13]$. Teknik ini paling 
efektif diterapkan pada tanah berpasir dan paling tidak efektif diterapkan pada tanah liat. Hal ini dikarenakan kandungan silika pada tanah berpasir yang lebih besar [13]. Kandungan silika berperan dalam menentukan kekuatan produk dan imobilisasi kontaminan pada kapsulasi mikro. Efisiensi kapsulasi mikro dalam mengimobiliisasi kontaminan hidrokarbon dalam tanah mencapai 85\% [13]. Kapsulasi mikro tidak efektif diterapkan untuk remediasi tanah yang mengandung senyawa dengan $\mathrm{pH}$ asam dan mengandung sulfat [14].

Seringkali proses kapsulasi makro dan kapsulasi mikro dikombinasikan. Sebagai contoh Randall dan Chattopadhyay [12] mengaplikasikan teknik kapsulasi pada limbah-limbah terkontaminasi logam berat merkuri. Limbah-limbah tersebut dikapsulasi dengan menggunakan polimer sulfur.

Semen polimer sulfur yang telah dicairkan dituangkan di atas dan disekitar limbah hingga limbah berbentuk monolit. Untuk kapsulasi mikro unsur merkuri berwujud cair, dilakukan pencampuran dengan bubuk semen polimer sulfur dalam bejana reaksi yang dipanaskan pada suhu $40{ }^{\circ} \mathrm{C}$. Zat aditif seperti sodium sulfida dan triisobutil fosfin sulfida dapat ditambahkan pada tahap ini. Selanjutnya semen polimer sulfur tambahan dituangkan pada campuran dan dipanaskan pada suhu $55^{\circ} \mathrm{C}$ untuk membentuk campuran yang homogen.

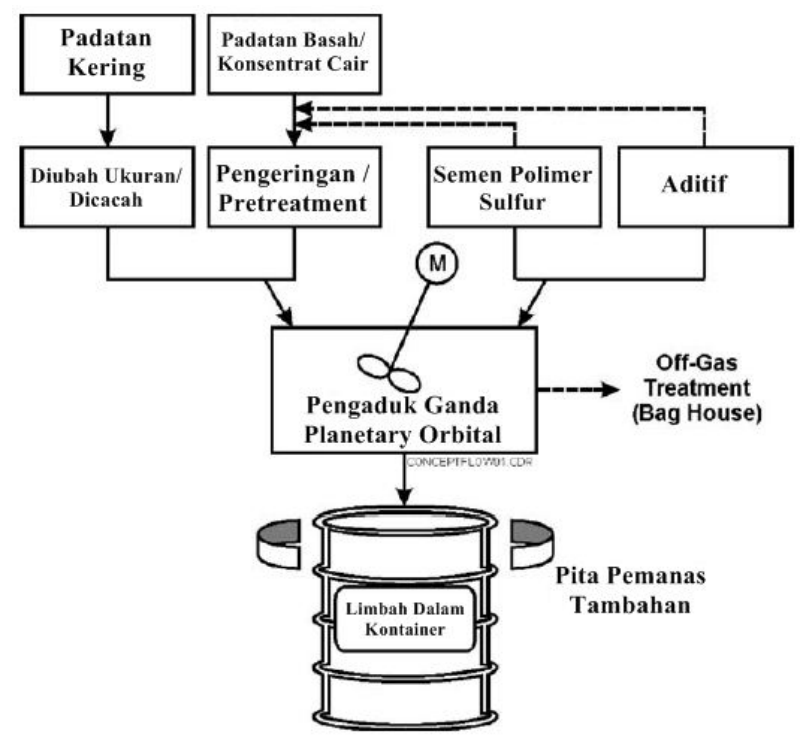

Gambar 2. Stabilisasi/Solidifikasi dengan Polimer Sulfur [12]

Keuntungan dari teknologi S/S dengan polimer sulfur adalah:

1. Limbah dengan konsentrasi merkuri yang tinggi dapat diatasi dengan efektif.

2. Proses menggunakan suhu yang relatif rendah (125-140 $\left.{ }^{\circ} \mathrm{C}\right)$

3. Permeabilitas dan porositas rendah dibandingkan semen portland.

4. Ketahanan tinggi terhadap lingkungan yang korosif.

5. Kekuatan mekanis tinggi.

6. Mudah untuk diimplementasikan karena alat pengadukan dan penuangan mudah tersedia.

7. Lebih mudah digunakan dibandingkan dengan bahan termoplastik lain seperti polyethylene.

8. Semen polimer sulfur dapat dilelehkan dan diformulasikan ulang.

Sedangkan kekurangan dari teknologi ini adalah:

1. Kehilangan merkuri akibat penguapan dapat terjadi sehingga membutuhkan pengendalian.

2. Limbah larutan harus dikeringkan sebelum pengolahan.

3. Semen polimer sulfur dapat menimbulkan rongga udara yang berlebih bila didinginkan terlalu cepat.

4. Potongan logam dengan massa termal yang besar membutuhkan pemanasan awal untuk mencegah terbentuknya rongga udara.

5. Tidak kompatibel dengan larutan alkali kuat, agen oksidasi kuat, pelarut aromatik atau terklorinasi, atau jenis tanah liat.

6. Penanganan semen polimer sulfur perlu penanganan teknis yang baik untuk mengurangi kemungkinan pengapian dan ledakan yang membahayakan.

7. Bila temperatur yang berlebih terbentuk, semen polimer sulfur akan mengeluarkan gas hidrogen sulfida dan uap sulfur.

\section{Kapsulasi Termoplastik}

Kapsulasi termoplastik atau kapsulasi polimer adalah teknologi pengolahan limbah dengan menggunakan polimer termoplastik untuk mensolidifikasi limbah B3 secara efektif dan aman. Umumnya polimer bersifat inert, mampu mengatasi beban limbah yang tinggi dibandingkan dengan enkapsulasi semen konvensional, dan mampu menciptakan karakteristik limbah yang rendah pelindian dan kuat tekan yang baik dalam waktu yang lama [15].

Limbah yang akan diolah diayak terlebih dahulu hingga didapatkan ukuran partikel sebesar 0,3-0,07 mm. Kemudian limbah dicampurkan dengan polimer plastik dan diletakkan pada wadah tertutup dan diaduk dengan screw extruder pada kecepatan $50 \mathrm{rpm}$ dan suhu $220{ }^{\circ} \mathrm{C}$ sehingga didapatkan matriks limbah yang homogen [16].

Jenis limbah yang sesuai untuk diolah dengan metode ini adalah limbah yang mengandung senyawa halida, limbah yang mengandung organik padat seperti resin, plastik, dan tar. Sedangkan untuk limbah B3 yang mengandung asam (memiliki $\mathrm{pH}$ rendah), perlu dinetralkan terlebih dahulu sebelum dicampur [14].

Tabel 1.

Contoh Aplikasi Kapsulasi Termoplastik

\begin{tabular}{llllc}
\hline \hline No & Jenis Limbah & Bahan Pengikat & Sumber \\
\hline 1 & $\begin{array}{l}\text { Limbah } \\
\text { tercampur }\end{array}$ & B3 & $\begin{array}{l}\text { LDPE (low density polyethylene) } \\
\text { daur ulang 20 }-60 \% \text { dengan indeks } \\
\text { leleh 22. }\end{array}$ & {$[15]$} \\
\hline 2 & $\begin{array}{l}\text { Fraksi non metal } \\
\text { dari PCB (printed } \\
\text { circuit board) }\end{array}$ & $\begin{array}{l}\text { HDPE (high density polyethylene) } \\
\text { daur ulang 50\% dan 6 phr (part per } \\
\text { hundred) MAPE } \\
\text { polyethylene) }\end{array}$ & {$[16]$} \\
\hline \hline
\end{tabular}

\section{Vitrifikasi}

Vitrifikasi adalah pengolahan termal yang mengubah limbah menjadi gelas atau bahan kristalin. Kebanyakan proses vitrifikasi beroperasi pada suhu $1200^{\circ} \mathrm{C}$ atau lebih. Pada suhu 
ini, semua bahan organik dan beberapa bahan anorganik (seperti sianida, nitrat) telah hancur. Senyawa organik akan membentuk gas (seperti karbon dioksida, uap air, nitrogen oksida, sulfur) saat berinteraksi dengan senyawa organik lain dalam lelehan, atau dengan oksigen saat keluar dari proses.

Produk vitrifikasi tersusun dari tiga kelas oksida: zat pembentuk gelas, stabilisator, dan fluks. Zat pembentuk gelas yang utama adalah silika $\left(\mathrm{SiO}_{2}\right)$. Fluks mengurangi suhu leleh dan viskositas lelehan serta meningkatkan konduktivitass listriknya. Logam alkali oksida dan alkali tanah oksida adalah bahan utama fluks. Stabilisator meningkatkan durabilitas gelas. Stabilisator utamanya tersusun atas alkali tanah oksida dan alumina. Limbah yang mengandung timbal dan kromium juga masuk dalam pembentukan gelas dan menjadi bagian dari produk vitrifikasi yang menyerupai gelas.

Secara teknis vitrifikasi in situ dapat dijelaskan sebagai berikut. Arus listrik dialirkan ke dalam tanah, hingga menimbulkan panas. Akibatnya tanah akan mencair, menjadi massa lelehan yang bersifat lebih konduktif dan menjadi medium transfer panas yang terus mengembang. Gambar 3 menggambarkan Vitrifikasi secara in situ.

Teknologi vitrifikasi in plant pada dasarnya merupakan teknologi pembuatan gelas dengan penggunaan tungku yang dioperasikan pada suhu $1600^{\circ} \mathrm{C}$. Sebagai starter digunakan campuran gelas daur ulang, abu terbang, dan kapur untuk memulai proses. Selanjutnya tanah yang terkontaminasi dikontakkan pada tungku untuk pelelehan dan peleburan selama $5 \mathrm{jam}$. Tanah yang memadat sebagai hasil vitrifikasi dapat dimanfaatkan sebagai bahan agregat untuk pembuatan jalan [6,7]. Gambar 3 menunjukkan sketsa tanah tercemar saat vitrifikasi dan setelah vitrifikasi [6].

Keuntungan vitrifikasi adalah [17]:

1) Vitrifikasi ex situ merupakan teknologi yang berkembang dengan baik.

2) Mobilitas kontaminan dikurangi / dihilangkan.

3) Massa yang sudah tervitrifikasi mampu menahan pelindian untuk periode waktu geologis.

Sedangkan kerugian vitrifikasi adalah:

1) Proses membutuhkan energi yang intensif dan temperatur yang tinggi hingga mendekati $2000 \mathrm{~K}$.

2) Air dalam tanah mempengaruhi operasi dan meningkatkan biaya total proses vitrifikasi.

3) Gas yang keluar harus dikumpulkan dan diolah sebelum dilepaskan.

4) Vitrifikasi in situ dalam pengembangan skala pilot scale.

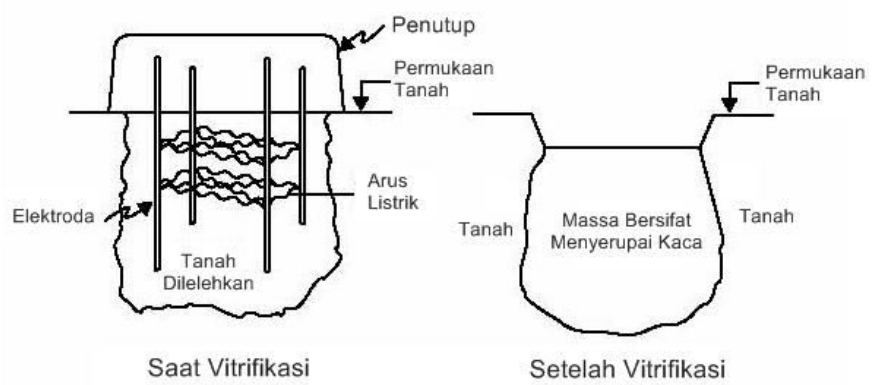

Gambar 3. Vitrifikasi secara In Situ [6]

\section{E. S/S Berbasis Semen Portland}

$\mathrm{S} / \mathrm{S}$ berbasis semen portland merupakan teknologi S/S secara kimia. Semen portland sangat cocok untuk digunakan sebagai bahan pengikat S/S pada remediasi tanah tercemar limbah B3 anorganik seperti logam berat [6,9]. Beberapa faktor yang mendukung adalah:

- Komposisi kimia semen portland yang konsisten.

- Menunjukkan hasil yang baik dalam proses setting, pengerasan, dan fiksasi logam

- Proses semen portland juga dapat meniru banyak reaksi proses pozzolanik, yang merupakan bagian dari teknologi $\mathrm{S} / \mathrm{S}$ saat ini.

S/S berbasis semen portland tidak efektif untuk meremediasi tanah tercemar limbah mengandung senyawa sulfat karena dapat menyebabkan keretakan dan menghambat setting. S/S berbasis semen juga efektif digunakan untuk remediasi tanah tercemar limbah B3 dengan $\mathrm{pH}$ rendah karena mampu menetralisir asam [14].

\section{F. S/S Berbasis Pozzolan}

$\mathrm{S} / \mathrm{S}$ berbasis pozzolan merupakan teknologi $\mathrm{S} / \mathrm{S}$ secara kimia. Pozzolan adalah bahan alam atau buatan yang sebagian besar kandungannya terdiri atas unsur-unsur silika dan alumina atau keduanya. S/S berbasis pozzolan dapat digunakan untuk remediasi tanah tercemar limbah B3 yang mengandung senyawa sulfat dan halida. S/S berbasis pozzolan juga efektif digunakan untuk remediasi tanah tercemar limbah B3 dengan $\mathrm{pH}$ rendah karena mampu menetralisir asam [14]. Contoh jenis pozzolan adalah fly ash, abu sekam padi, bentonit, dan tanah tras.

\section{V.MEKANISME STABILISASI/SOLIDIFIKASI}

\section{A. Absorpsi}

Limbah B3 dapat diikat secara fisik oleh bahan pengabsorpsi. Penggunaan bahan-bahan absorben dalam penanganan limbah B3 pada umumnya adalah untuk menyerap limbah yang bersifat cair agar lebih mudah ditangani. Oleh karena itu penggunaannya hanya bersifat temporer. Adapun bahan absorben yang bersifat pozzolanik atau dapat mengeras (misalnya abu terbang, lempung), dapat digunakan untuk jangka lebih lama [7].

Absorben yang paling umum digunakan diantaranya [9]:

- Tanah

- Abu terbang (Fly Ash)

- Debu semen kiln (Cement kiln dust)

- Debu kapur kiln (Lime kiln dust)

- Mineral lempung termasuk bentonit, kaolinit, vermiculite, dan zeolit.

- Serbuk gergaji

- Jerami

\section{B. Adsorpsi}

Adsorpsi adalah fenomena dimana kontaminan secara elektrokimiawi terikat dengan agen stabilisasi dalam matriks. Ikatan ini terjadi melalui ikatan hidrogen. Kontaminan yang secara kimiawi teradsorpsi oleh matriks stabilisasi lebih sukar terlepas ke lingkungan dibandingkan kontaminan yang tidak teradsorpsi. 
Stabilisasi limbah organik dengan tanah liat termodifikasi merupakan ilustrasi adsorpsi yang diterapkan pada limbah organik. Tanah liat termodifikasi diubah dengan mengganti kation anorganik yang dapat ditukar yang teradsorpsi pada permukaan tanah liat dengan kation rantai panjang. Sehingga tanah liat bersifat organofilik. Molekul limbah organik kemudian diadsorpsi ke tanah liat. Kekuatan ikatan penyerap harus diatasi bila molekul limbah organik terlepaskan ke lingkungan. Gambar 4 merupakan gambar limbah organik yang diadsorpsi pada tanah liat organophilic [9].

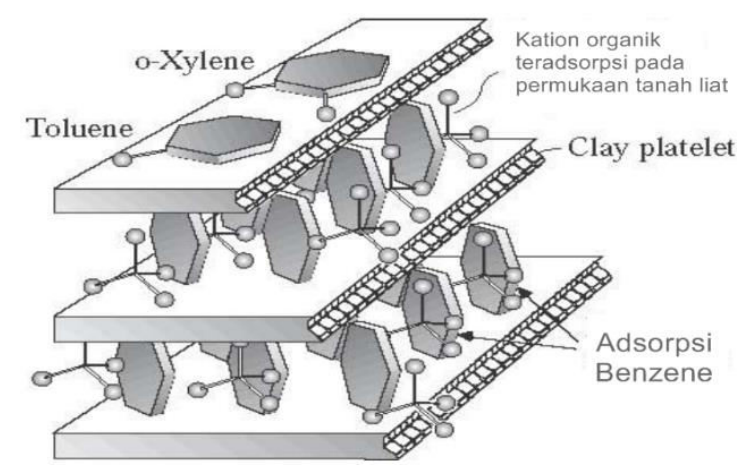

Gambar 4. Limbah Organik yang Diadsorpsi pada Tanah Liat Termodifikasi [9]

Adsorpsi juga terjadi pada stabilisasi/solidifikasi dari logam kationik juga dengan menggunakan zat semen atau mineral lain maupun tanah lempung. Adsorpsi dari logam kationik oleh zat semen atau mineral lain maupun tanah lempung sangat tergantung pada:

- Karakteristik kimia pada permukaan.

- Lapisan ganda bermuatan pada antarmuka fase padatcair.

- Densitas area adsorpsi.

- Komposisi dan $\mathrm{pH}$ media

Adsorpsi ion logam dapat menyebabkan interaksi kimia antara molekul di permukaan dan ion-ion yang teradsorpsi. Proses adsorpsi dimungkinkan secara fisik murni terjadi di alam. Gambar 5 menunjukkan bahwa bila sebuah ion diadsorpsi pada permukaan mineral (antarmuka padat-cair), maka sejumlah angka ekuivalen dari ion yang bersebrangan dengan permukaan harus juga diadsorpsi untuk menetralkan elektron dan membentuk "lapisan ganda bermuatan listrik" [18].

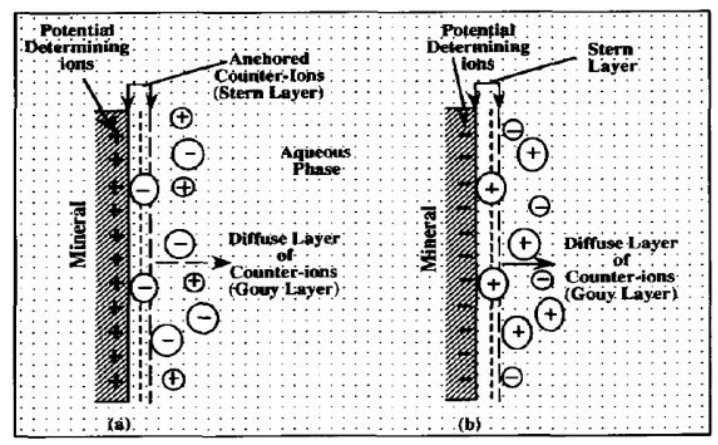

Gambar 5. Diagram Skematik dari Dua Lapisan Bermuatan Listrik pada
Permukaan Mineral dalam Fase Air; (a) dan (b) mengacu pada permukaan positif dan negatif [18]

\section{Mekanisme Pengikatan dengan Semen}

Semen merupakan bahan yang sering digunakan sebagai bahan pengikat $\mathrm{S} / \mathrm{S}$. Saat pencampuran semen dengan air, kalsium silikat terpisah menjadi silikat bermuatan dan ion-ion kalsium [18]. Ion-ion silikat bermuatan ini bersatu membentuk lapisan tipis pada permukaan butiran semen untuk mencegah interaksi permukaan semen dengan air. Hal ini memperlambat terlepasnya ion-ion kalsium dan silikat dari semen menuju air. Proses hidrasi awal diikuti oleh nukleasi dan pertumbuhan kristal heksagonal dari kalsium hidroksida yang memenuhi ruang dan rongga antar butiran semen. Sementara itu, partikel kalsium silikat hidrat mengendap keluar dari air menuju lapisan yang kaya akan silikat pada butiran semen dan secara bertahap membentuk struktur menyerupai jarum. Struktur ini saling menciptakan kontak dengan butiran semen lain dan membentuk lembar tobermorite. Gambar 6 menggambarkan proses hidrasi semen [18].

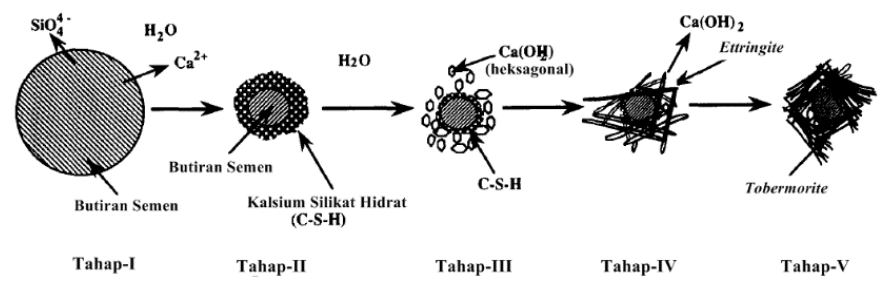

Gambar 6. Model Kristal dari Hidrasi Semen [18]

Cocke [19] melakukan penelitian S/S terhadap logam berat $\mathrm{Pb}$ dan semen sebagai pozzolan. $\mathrm{Pb}$ dilapisi oleh lapisan kalsium silikat yang mencegah hidrasi dan menjebak larutan jenuh dalam kantung yang membatasi.

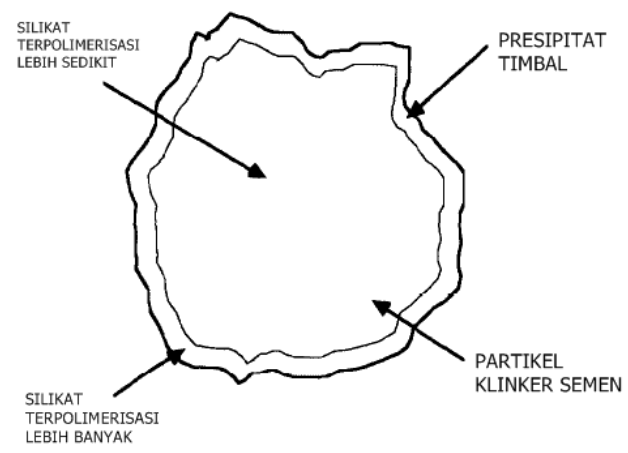

Gambar 3. 10 Sketsa Logam Berat Timbal yang Dilapisi Partikel Semen Pada Proses S/S [19]

Kontaminan logam berat $\mathrm{Pb}$ terperangkap di dalam matriks semen dan terkonversi menjadi bentuk yang stabil secara fisik dan kimia. Reaksi yang berlangsung saat proses S/S adalah:

$$
\begin{aligned}
& \mathrm{Pb}^{2+}+\mathrm{OH}^{-} \rightarrow \mathrm{Pb}(\mathrm{OH})_{2} \quad \text { (mengendap) } \\
& \mathrm{Pb}^{2+}+\mathrm{CO}_{3}{ }^{2-} \rightarrow \mathrm{PbCO}_{3} \text { (mengendap) }
\end{aligned}
$$

Logam berat $\mathrm{Pb}$ yang mengendap terperangkap dalam 
matriks semen yang terbentuk menyebabkan kontaminan terimobilisasi dan stabil secara fisik.

\section{KESIMPULAN}

Berdasarkan hasil studi yang telah dilakukan, maka dapat diambil kesimpulan sebagai berikut:

Mekanisme stabilisasi/solidifikasi adalah mengurangi sifat berbahaya limbah dengan cara mengurangi laju migrasi dan toksisitasnya. Laju migrasi dan toksisitas berkurang akibat terikatnya kontaminan limbah B3 karena penambahan bahan pendukung dan berubahnya sifat fisik limbah yang menurunkan kelarutan dan immobilisasi kontaminan dalam tanah. Teknologi stabilisasi/solidifikasi terbagi menjadi tiga bagian, yaitu secara fisik, kimia, dan termal.

Teknologi stabilisasi/solidifikasi yang dapat diterapkan untuk meremediasi tanah tercemar limbah B3 adalah kapsulasi mikro, vitrifikasi, dan stabilisasi/solidifikasi berbasis semen portland dan pozzolan. Sedangkan kapsulasi makro dan termoplastik efektif untuk mengolah limbah B3 padat.

Kapsulasi mikro efektif diterapkan untuk remediasi tanah berpasir yang tercemar limbah B3. Tanah berpasir memiliki kandungan silika yang besar yang berperan dalam imobilisasi kontaminan dan menentukan kekuatan produk. Kapsulasi mikro efektif diaplikasikan untuk tanah tercemar senyawa hidrokarbon. Kapsulasi mikro tidak efektif diterapkan untuk remediasi tanah yang mengandung senyawa dengan $\mathrm{pH}$ asam dan mengandung sulfat.

Vitrifikasi adalah teknologi S/S secara termal yang mampu digunakan untuk meremediasi tanah tercemar limbah B3 baik organik maupun anorganik. Imobilisasi kontaminan dilakukan dengan cara mengubah limbah menjadi gelas atau bahan kristalin. Teknologi vitrifikasi membutuhkan energi yang

besar dan menghasilkan gas yang perlu diolah sebelum dilepaskan ke lingkungan.

$\mathrm{S} / \mathrm{S}$ berbasis semen portland dan pozzolan baik diterapkan untuk remediasi tanah tercemar limbah $\mathrm{B} 3$ dengan $\mathrm{pH}$ rendah dan mengandung senyawa halida. $\mathrm{S} / \mathrm{S}$ berbasis pozzolan mampu mengatasi kontaminan mengandung senyawa sulfat, sedangkan $\mathrm{S} / \mathrm{S}$ berbasis semen portland tidak mampu mengatasinya.

\section{DAFTAR PUSTAKA}

[1] Facchinelli, A., Sacchi, E., Mallen, L. 2001. Multivariate statistical and GIS-based Approach to Identify Heavy Metal Sources in Soils". Environmental Pollution 114: 313-324.

[2] Palar, H. 2008. Pencemaran dan Toksikologi Logam Berat. Rineka Cipta, Jakarta.

[3] Wardhana, W.A. 2001. Dampak Pencemaran Lingkungan. Yogyakarta: Andi Offset.

[4] Virkutyte, J., Sillanpaa, M., Latostenmaa, P. 2002. Electrokinetic soil remediation-critical overview. The Science of the Total Environment 289: 97-121.

[5] Dermatas, D. dan Meng, X. 2003. Utilization of fly ash for stabilization/solidification of heavy metal contaminated soils. Engineering Geology 70: 377-394.

[6] Spence, R.D. dan Shi, C. 2005. Stabilization and Solidification of Hazardous, Radioactive, and Mixed Wastes. CRC Press.
[7] Trihadiningrum, Y. 2016. Pengelolaan Limbah Bahan Berbahaya dan Beracun. Teknosain, Yogyakarta.

[8] Wiqoyah, Q. 2007. Pengaruh Tras Terhadap Parameter Kuat Geser Tanah Lempung. Jurnal Dinamika Teknik Sipil 7: 147-153.

[9] LaGrega, M.D., Buckingham P.I., Evans, J.C. 2001. Hazardous Waste Management. McGraw-Hill, Inc: Singapore.

[10] Paria, S. dan Yuet, K. 2006. Solidification/Stabilization of Organic and Inorganic Contaminants Using Portland Cement. A Literature Review. Environmental Reviews 14: 217-255

[11] Singh, D., Wagh, A. ., Tlustochowicz, M., Jeong, S. 1998. Phosphate Ceramic Process for Macroencapsulation and Stabilization of Low-level

[12] Debris Wastes. Waste Management 18: 135-143.

[13] Randall, P., dan Chattopadhyay, S. 2004. Advances in Encapsuation Technologies for The Management of Mercury-contaminated Hazardous Wastes. Journal of Hazardous Material B114: 211-223.

[14] Wami, E. N., dan Nmegbu, C. G. J. 2015. Micro-Encapsulation Technique for Effective Remediation of Hydrocarbon Contaminants. International Journal of Scientific \& Engineering Research 6, 8: 815823.

[15] US EPA. 1986. Handbook for Stabilization/Solidification of Hazardous Wastes. Office of Research and Development. EPA/540/2-86/1001; Cincinnati, $\mathrm{OH}$.

[16] Adams, J.,W. dan Kalb, P., D. 2001. Sulfur Polymer Stabilization/Solidification (SPSS) Treatability of Los Alamos National Laboratory Mercury Waste. Brookhaven National Laboratory, USA.

[17] Muniyandi, S. K., Sohaili, J., Hassan. A. 2014. Encapsulation of Nonmetallic Fractions Recovered from Prnted Circuit Boards Waste with Thermoplastic. Journal of The Air and Waste Management Association 64: 9, 1085-1092.

[18] Castelo-Grande T., Barbosa D. 2003. Soil Decontamination by Supercritical Extraction. Electronic Journal of Environmental, Agricultural and Food Chemistry 2, 2: 331-336.

[19] Yousuf, M., Mollah, A., Vempati, R.K., Lin, T.C., David, L.C. 1995. The Interfacial Chemistry of Solidification/Stabilization of Metals In Cement and Pozzolanic Material Systems. Waste Management 15, 2: 137-148.

[20] Cocke, D. L. 1990. The Binding Chemistry and Leaching Mechanisms of Hazardous Substances in Cementitious Solidification/Stabilization Systems. Journal of Hazardous Materials 24; 231-253. 